\title{
Carta desde las Islas de las Especias: una nueva edición de la misiva de Juan Bautista de Punzorol
}

\author{
Letter from the Spice Islands: a new edition of \\ the missive from Juan Bautista de Punzorol
}

\author{
Braulio Vázquez Campos
}

ORCID iD: https://orcid.org/0000-0001-5801-1990

Archivo General de Indias, Sevilla, España

Estudio y edición crítica de la carta de Juan Bautista de Punzorol, maestre de la Trinidad, nao capitana de Fernando de Magallanes, escrita el 21 de diciembre de 1521 desde Tidore (islas Molucas). El original, actualmente en paradero desconocido, llegó a España en la nao Victoria capitaneada por Juan Sebastián Elcano en su viaje de regreso desde las Molucas. Una traducción al italiano fue a parar a la República de Ragusa, donde se hizo otra copia cuya transcripción publicara Eugene Gelcich en 1889 y tradujera al castellano Toribio Medina en 1920. Se ofrecen aquí una nueva transcripción y traducción de ese ejemplar, que arrojan nueva luz sobre la Armada de la Especiería.

Palabras Clave: Punzorol; Elcano; Magallanes; primera circunnavegación; Islas Molucas; especias; comercio marítimo; Ragusa.

Study and critical edition of the letter of Juan Bautista de Punzorol, master of the Trinidad, Magellan's flagship, written from Tidore, in the Moluccas, on December 21, 1521. A translation into Italian reached the Republic of Ragusa, where another copy was made, the transcription of which was published by Eugene Gelcich in 1889 and translated into Spanish by Toribio Medina in 1920. A new transcription and translation of this copy are offered here, which shed new light on the Spice «Armada».

KeYwords: Punzorol; Elcano; Magellan; First Circumnavigation; Maluku Islands; Spices; Maritime Trade; Ragusa.

Copyright: (C) 2021 CSIC. Este es un artículo de acceso abierto distribuido bajo los términos de la licencia de uso y distribución Creative Commons Reconocimiento 4.0 Internacional (CC BY 4.0). 


\title{
Carta desde las Molucas
}

\author{
El sábado, 21 del mes, día de Santo Tomás [...], nos dijeron \\ que el tiempo era excelente para el viaje y que debíamos partir \\ cuanto antes; pero tuvimos que esperar a que nos trajesen las \\ cartas que nuestros compañeros que se quedaban en las Maluco \\ mandaban a España, y no pudimos levar anclas hasta el mediodía. ${ }^{1}$
}

Aquel 21 de diciembre de 1521, cuenta Antonio Pigafetta, los supervivientes de la expedición de Magallanes que habían llegado a las islas de las Especias el 8 de noviembre anterior, y que no iban a poder dar la vuelta al mundo en la nao Trinidad junto a la nao Victoria, se afanaban por escribir a sus amigos, familiares y patronos en Castilla. Confiaban en que el capitán Elcano tuviera éxito en su empeño de regresar a España por la vía del Oeste, $\mathrm{y}$, de este modo, lograra llevar las noticias de los que quedaban atrás.

Tres días antes, nadie pensaba en tales cartas, sino en hacerse a la mar cuanto antes. El día 18 de diciembre, las dos naos que restaban de las cinco que habían compuesto la «Armada de la Especiería», la Trinidad y la Victoria, se disponían a salir juntas del puerto de Tidore, cargadas hasta el límite del preciado clavo. Sin embargo, la Victoria, que se había adelantado, viró en redondo para averiguar qué le sucedía a su nao capitana, que apenas había podido levar anclas. Se dieron cuenta entonces de que existía una vía de agua en la quilla, aunque no conseguían localizar por dónde entraba el mar a chorros: de nada sirvió vaciar el barco, volcarlo sobre un costado, emplear buceadores nativos... Finalmente, se descubrió que se había abierto un agujero de cuatro palmos, que no podían reparar ni por dentro ni por fuera, en palabras del propio maestre del barco, el autor de la misiva cuya nueva edición nos ocupa aquí.

¿Quién era este maestre? Su nombre, o más exactamente su apellido, es registrado de forma variopinta en la documentación. He adoptado como forma principal la de «Juan Bautista de Punçorol» (o «Punzorol»), pues así figura en la relación de sueldos de los tripulantes de la expedición magallánica, ${ }^{2}$ aunque en su lengua nativa respondería al nombre de Giovanni

1 Pigafetta, 2012 [c. 1522], 303. El santo al que se refiere es santo Tomás Apóstol, del que se recuerda su martirio el 21 de diciembre, mientras que el traslado de sus despojos se conmemora el 3 de julio.

2 Archivo General de Indias, Sevilla (AGI), Contratación, 5090, 1. 4, f. 42r. Disponible en: http://pares.mcu.es/ParesBusquedas20/catalogo/show/108426?nm [Consultado: 18/06/2020]. «Iuan Bautista de Ponceuera Ginoués» le llama Herrera, 1601, déc. II, 1. IV, cap. IX, 130. 
Battista di Ponzorone. ${ }^{3}$ Y es que, tal y como leemos en las informaciones sobre sueldos de aquella armada, Juan Bautista «Ponçorón» era natural de «Çistre, que es en la ribera de Génova» (desconocemos si Sestri Levante o, con más probabilidad, Sestri Ponente), y que estaba casado con una tal Blanca. ${ }^{4}$ Sabemos que tenía al menos un hijo, Domingo, que se enroló también a las órdenes de Magallanes como marinero en la nao Santiago. Autores como Hugues y Avonto pusieron a nuestra disposición múltiples noticias de Juan Bautista, pero aquí solo me detendré en las más relevantes para el propósito de este trabajo. ${ }^{5}$ Teniendo alrededor de cincuenta años, fue de los primeros en alistarse en la Armada de la Especiería, convirtiéndose en uno de los hombres de confianza de su Capitán General. Estuvo a cargo del reclutamiento de la marinería, lo que aprovechó para incorporar a muchos compatriotas suyos. Se le adjudicó el puesto de maestre de la nao Trinidad, ${ }^{6}$ uno de los de mayor responsabilidad, a buen seguro por sus grandes conocimientos náuticos adquiridos al servicio de Portugal. Así se deduce de lo que en 1523 el gobernador portugués de la moluqueña isla de Ternate, Antonio Brito, diría de él: era «el principal que ellos traían, porque después que mataran a Fernando de Magallanes él fue el que trajo esta armada al Maluco, y se llama Juan Bautista, ${ }^{7}$ y anduvo en las naos de Vuestra Alteza en Portugal». ${ }^{8}$ Razón no le faltaba a Brito. Sabemos que tras la muerte en batalla de Magallanes en Mactán (islas Filipinas, 27 de abril de 1521), el asesinato a traición de buena parte de la oficialidad de la expedición en el conocido como «banquete de Cebú» (1 de mayo de 1521), y el errático y corrupto caudillaje del capitán João Lopes Carvalho (desde mayo hasta el 17 de septiembre de 1521), ${ }^{9}$ Juan Bautista se convirtió en miembro del

3 La forma «Ponzorone» la propuso Pessagno, 1930, 78, en su reseña de Noberasco, 1929.

4 Se le llama allí «Ponçolón». AGI, Contaduría, 425, n. 1, r. 1, f. 63r. Disponible en: http:// pares.mcu.es/ParesBusquedas20/catalogo/show/7344884?nm [Consultado: 18/06/2020].

5 Hugues, 1894, 252-262. Avonto, 1992, 39-51.

6 «Relación de la gente que ba en las naos que su Alteza manda ynviar para el descubrimiento de la espeçería», AGI, Patronato, 34, r. 6 [2], f. 1r. Disponible en: http://pares.mcu.es/ParesBusquedas 20/catalogo/show/122215?nm [Consultado: 17/06/2020].

7 Había más tripulantes con ese nombre, pero el único con rango y perfil técnico coincidente con la descripción de Brito era Punzorol.

8 Carta de Antonio Brito a Juan III de Portugal, Ternate, 6 de mayo de 1523, Arquivo Nacional Torre do Tombo, Lisboa (ANTT), PT/TT/GAV/18/2/25, cita en f. 9v. Disponible en: https://digitarq.arqui vos.pt/viewer?id=7661648 [Consultado: 17/06/2020]. Se halla transcrita en As Gavetas da Torre do Tombo, VIII, 1970, 201-215 (cita en 212). Traducida al español y publicada parcialmente en Medina, 1920a, 99-104. Transcripción libre de Juan Bautista Muñoz en Fernández de Navarrete, 1837, IV: 305-311.

9 En esa fecha, Elcano fue elegido capitán de la Victoria y Gómez de Espinosa de la Trinidad, sustituyendo a Lopes Carvalho. AGI, Contaduría, 425, n. 1, r. 1, ff. 1r y 62r. Disponible en http://pares. mcu.es/ParesBusquedas20/catalogo/show/7344884?nm [Consultado: 18/06/02020]. 
triunvirato de «governadores» que dirigiría la Armada de la Especiería a su objetivo primigenio, las islas Molucas. Sus dos compañeros en el mando fueron los capitanes Gonzalo Gómez de Espinosa, en la Trinidad, y Juan Sebastián de Elcano, en la Victoria. De esta privilegiada posición de Punzorol no solo nos informa él mismo en su mencionada carta, sino también el escribano y contador de la armada, Martín Méndez, en el documento tradicionalmente conocido como «Paces del Maluco». ${ }^{10}$

Pero volvamos al momento en el que el maestre de la Trinidad se enfrentó a la grave avería en el casco de su embarcación. Se vio enseguida que sería necesario «poner a monte» — varar- el navío, y sanear y hasta reconstruir el casco durante meses para volver a ponerlo a flote. Cincuenta días creía Juan Bautista que emplearía en ello: requirió más de cien. Todos los testimonios presenciales coinciden en que las tripulaciones resolvieron que la Victoria partiera enseguida, tanto para aprovechar los vientos favorables como para escapar a la que se creía inminente llegada de una armada portuguesa. ${ }^{11}$ En efecto, los portugueses de Malaca, que no podían consentir que sus rivales ibéricos amenazaran su monopolio del comercio especiero, estaban preparando una armada con trescientos hombres para dirigirse a las Molucas y establecer una base permanente. ${ }^{12}$

Así pues, nos encontramos con que el 21 de diciembre los expedicionarios de la Victoria se disponían a seguir la vía del Índico para alcanzar el cabo de Buena Esperanza, alejándose de la transitada ruta portuguesa que conectaba Malaca con la India, ${ }^{13}$ mientras que el barco que quedaba en el

10 AGI, Indiferente, 1528, n. 1, f. 2r. http://pares.mcu.es/ParesBusquedas20/catalogo/show/ 304065?nm [Consultado: 17/06/2020].

11 Piloto genovés anónimo, 1893 [c. 1522], 284-285 (hay traducción española: Piloto genovés anónimo, 2012 [c. 1522], 135); Mafra, 2012 [c. 1540], 181-182; Pigafetta, 2012 [c. 1522], 302; «Auto das perguntas que se fizeram a dois espanhois que chegaram á fortaleza de Malaca vindos de Timor na companhia de Álvaro Juzarte, capitão de um junco, Malaca, 1 de junio de 1522», ANTT, PT/TT/ CC/2/101/87. Disponible en: https://digitarq.arquivos.pt/viewer?id=3801974 [Consultado: 18/06/2020]. Abunda en estas informaciones Oliveira, 2002 [c. 1570], 53.

12 Ocho barcos en Lopes de Castanheda, 1554, VI: 22-23; y seis en Barros, 1563, f. 141v. El marinero de la Trinidad Ginés de Mafra no especifica el número de barcos en su crónica (Mafra, 2012 [c. 1540], 182), pero en el interrogatorio que tuvo que responder a su regreso en 1527 habla de «çinco velas»; en el mismo testimonio, el piloto León Pancado dijo que fueron siete. AGI, Patronato, 34, r. 27, ff. 4v y 6v. Disponible en: http://pares.mcu.es/ParesBusquedas20/catalogo/show/122236?nm [Consultado: 18/06/2020]. Pigafetta (2012 [c. 1522], 290) habla de seis barcos de guerra que iba a comandar Diego Lopes de Sequeira, virrey de la India portuguesa, pero en un momento anterior a este.

13 Según contó Martín de Ayamonte, grumete de la nao Victoria, a sus captores portugueses, Elcano impuso su criterio frente al maestre Miguel de Rodas y al piloto Francisco Albo, que abogaban por «ir por Malaca». Malaca, 1 de junio de 1522, ANTT, PT/TT/CC/2/101/87. Disponible en: https:// digitarq.arquivos.pt/viewer?id=3801974 [Consultado: 18/06/2020]. 
dique seco tomaría, una vez «corregido» o reparado, la derrota del Pacífico para intentar alcanzar el Darién, en el istmo de Panamá, y allí contar con el auxilio de los castellanos establecidos desde hacía una década. Nuestro maestre genovés, tanto en la carta que veremos a continuación, como en otras escritas junto al piloto León Pancado, ${ }^{14}$ corrobora los testimonios en este sentido, ${ }^{15}$ hablando de la «Tierra Firme de la parte del sur», donde «hizo Andrés Niño las caravelas». ${ }^{16}$ Niño, piloto de la Casa de la Contratación, había partido de Sanlúcar una semana antes que Magallanes, también en busca de un paso que cruzara el Nuevo Mundo hacia las Molucas, pero por Centroamérica. ${ }^{17}$

El maestre Juan Bautista entregaría a su hijo Domingo Bautista, que partía en la Victoria, la carta escrita en aquellos últimos momentos a un noble destinatario que no se nombra. No lo sabían, pero durante aquella despedida entre lágrimas y salvas de artillería de las dos naos ${ }^{18}$ sería la última vez que se vieran: Domingo fallecería frente a la costa de Guinea el 14 de junio de $1522,{ }^{19}$ mientras que su padre, después de un periplo digno de memoria por el Pacífico Norte en la nao Trinidad, ${ }^{20}$ sería capturado por

14 Es conocido en la historiografía como «Pancaldo», pero él firmaba como «León Pancado», y así se le llama en las declaraciones de sus compañeros (AGI, Patronato, 34, r. 27, ff. 6v y 19r.) Disponible en: http://pares.mcu.es/ParesBusquedas20/catalogo/show/122236?nm [Consultado: 18/06/2020].

15 Pigafetta, 2012 [c. 1522], 302. Carta de Antonio Brito a Juan III de Portugal, Ternate, 6 de mayo de 1523, ANTT, PT/TT/GAV/18/2/25, f. 3v, traducida y publicada parcialmente por Medina, 1920a, 100. Piloto genovés anónimo, 2012 [c. 1522], 135. Compárese el relato de Transilvano, 2012 [1522], 64.

16 Cartas en castellano, firmadas por Juan Bautista y el piloto León Pancado, los días 20 y 25 de octubre de 1525 durante su cautiverio en Mozambique: la del día 20, dirigida a un «Muy Reverendísimo Señor» del que no sabemos el nombre, en ANTT, PT/TT/GAV/15/10/34, y transcrita en As gavetas da Torre do Tombo, IV (gaveta XV, maços 1-15), 1964, 316-319; la del día 25, dirigida a Carlos I, en ANTT, PT/TT/GAV/17/6/24, y transcrita en As gavetas da Torre do Tombo, VII (gaveta XVII, maços 3-9), 1968, 381-384. Las citas son del segundo documento.

17 El 18 de junio de 1519 se había ordenado al gobernador de Castilla del Oro entregar a Andrés Niño y a su compañero Gil González Dávila, para su expedición al Mar del Sur, los barcos que llevaba Vasco Núñez de Balboa cuando iba a realizar ese mismo descubrimiento, pero sin licencia. Para entonces, Balboa ya había sido ejecutado por Pedrarias, aunque no se sabía en España. AGI, Indiferente General, 420, 1. 8, f. 65v.

18 Pigafetta, 2012 [c. 1522], 303.

19 Relación de tripulantes de la Armada enviada al descubrimiento de la Especiería fallecidos, desertores o dejados en las Molucas, c. 1522, AGI, Patronato, 34, r. 11, f. 5r. Disponible en: http://pares. mcu.es/ParesBusquedas20/catalogo/show/122220?nm [Consultado: 09/07/2020]. La fecha del fallecimiento figura erróneamente como 14 de julio en la relación de los sueldos debidos a los expedicionarios, AGI, Contaduría, 425, n. 1, r. 1, f. 25v. Disponible en: http://pares.mcu.es/ParesBusquedas20/catalogo/ show/7344884?nm [Consultado: 09/07/2020].

20 Comellas, 2012, 149-152. Vázquez Campos, 2019, 301-307. Mazón Serrano, 2020, 163-174. 
los portugueses, protagonizaría una fracasada huida desde la India y moriría en Mozambique hacia finales de 1525, a consecuencia de las penalidades del cautiverio. ${ }^{21}$ En su agonía pudo al menos tener el consuelo de la compañía del piloto León Pancado, que sí lograría llegar a Castilla pocos meses después.

\section{Un poco de historia archivística}

La carta de Juan Bautista desembarcó sin duda en España, probablemente en poder del capitán de la Victoria. No conocemos el paradero actual de la misiva, si es que aún existe; lo que sí sabemos es que dos traducciones a dialectos italianos fueron a parar a los archivos de la República de Ragusa, la actual Dubrovnik, y que en su camino la acompañaron otras dos del célebre aviso que Juan Sebastián Elcano dirigió al rey Carlos I cuando completó su vuelta al mundo el 6 de septiembre de $1522 .{ }^{22}$ Pero ¿cómo y por qué llegaron a orillas del Adriático? ¿Y por qué se ha venido utilizando en la historiografía reciente tan solo una de esas dos versiones de la carta de Punzorol? Quizá lo mejor sea comenzar por el final, por la historia de cómo fueron dados a conocer estos documentos entre finales del siglo XIX y comienzos del XX, y por mis propias investigaciones en los Archivos Estatales en Dubrovnik.

La primera (y única, que yo conozca) transcripción completa de una de las traducciones de las cartas de Punzorol y de Elcano se la debemos a Eugene Gelcich (o Jelčić), director entre 1881 y 1895 de la Real e Imperial Escuela Náutica en Lussinpiccolo (actualmente Mali Lošinj, en Croacia), uno de los principales centros de construcción naval del Imperio austrohúngaro. Eugene publicó en 1889 el hallazgo de su hermano Josef (o Josip), que se desempeñaba como real e imperial conservador de arte y monumentos históricos en Ragusa, incluidos los antiguos archivos de la República. ${ }^{23}$

21 Para los últimos años del maestre Juan Bautista, véase Medina, 1920a, CCCCXXV-CCCCXVI; Avonto, 1992, 47-51. Su fuente es el interrogatorio a León Pancado de 1527, AGI, Patronato, 34, r. 27, f. 5r. Disponible en: http://pares.mcu.es/ParesBusquedas20/catalogo/show/122236?nm [Consultado: $18 / 06 / 2020]$.

22 Tampoco de esta se conserva el original, aunque sí varias traducciones al italiano, otra al latín y una copia en castellano: Carta de Juan Sebastián Elcano dando noticia de la primera vuelta al mundo, Sanlúcar de Barrameda, 6 de septiembre de 1522, AGI, Patronato, 48, r. 20. Disponible en: http://pares.mcu.es/ParesBusquedas20/catalogo/show/7343174?nm [Consultado: 18/06/2020].

23 Gelcich, 1889, 2. Gavrilovic, 1965, 596. 
En 1931, el historiador local Jorjo Tadic publicó novedades sobre documentos relativos al viaje «de Magallanes» en el Archivo de Ragusa: no solo encontró una carta que era la clave para identificar al responsable de enviar allí traducciones de las cartas de Elcano y de Punzorol (Iacopo Bannisio, del que luego daré más detalles), sino que ofrecía noticia de dos versiones de estas, dando a entender que eran las mismas que editara Gelcich. Pero no era así: la descripción que hizo Tadic del alarmante estado de conservación de aquellos documentos nos lleva a concluir que eran otros distintos a los estudiados por Gelcich, a quien no podía haber pasado desapercibida tal circunstancia. Es más, las copias transcritas completamente por este último en 1889 se encuentran aún hoy en un excelente estado de conservación, y son perfectamente legibles, como puede apreciarse en las imágenes que se incluyen más adelante. En cambio, las cartas descubiertas en 1931 sufrían una corrosión tal de las tintas sobre el soporte, que este se desintegraba al menor contacto. De hecho, Tadic hacía un llamamiento a fotografiar ambas cartas y preservarlas, pues pronto acabarían por deteriorarse irreversiblemente. Desgraciadamente, no nos dejó una transcripción completa de su hallazgo, sino solo una traducción, y resumida, al serbocroata. ${ }^{24}$

La situación de las cartas de Elcano y de Punzorol halladas por Tadic había empeorado en la década de 1960, cuando tanto el director de los Archivos de Ragusa, Vinko Foretic, ${ }^{25}$ como el estudioso Stoyan Gravilovic constataban que ni siquiera estaban localizadas. Sin embargo, este último argumentó de manera convincente, tras comparar las traducciones parciales de Tadic con la transcripción completa y literal de Gelcich, que las versiones editadas por este último no eran sino una copia realizada en algún momento del siglo XVI (fecha apuntada en las anotaciones de archivo que se observan en ella) por un desconocido escribano raguseo, a partir de las traducciones italianas enviadas por Iacopo Bannisio que a la sazón no eran accesibles al investigador. ${ }^{26}$ En conclusión, en Dubrovnik habían contado en algún momento no con dos, sino con cinco documentos relativos a la primera vuelta al mundo: por una parte, el despacho diplomático de Bannisio y las dos traducciones al italiano que él envió al Gobierno de Ragusa en 1523 , en pésimo estado de conservación cuando fueron descubiertos y

24 Tadic, 1931, 239-241. Citado en Gavrilovic, 1965, 597 y 603-608.

25 Foretic, 1960. Citado en Gavrilovic, 1965, 597.

26 Gavrilovic, 1965, 601. Gavrilovic decía de las versiones de Bannisio que «are unobtainable at present», mientras que el director del Archivo de Ragusa, Foretic, había declarado en una carta: «We have not yet been able to trace these two reports in the still older version» (ibidem, 608). 
estudiados por Tadic; por otra, dos copias de dichas traducciones volcadas durante el siglo XVI en la ciudad dálmata a un italiano trufado de léxico véneto, ${ }^{27}$ editadas por Gelcich. Vinko Foretic manifestó que cuando las traducciones originales de Bannisio fueran halladas de nuevo, decidirían si se podían fotografiar o transcribir para garantizar su pervivencia. ${ }^{28} \mathrm{El}$ último capítulo de esta historia es mi reciente consulta a los Archivos Estatales en Dubrovnik, en la que les detallaba todos estos antecedentes, y que fue respondida el 15 de julio de 2020 de este tenor: los documentos descubiertos por Tadic se encontraban, en efecto, inmanejables por la agresiva acción de sus tintas; sin embargo, en algún momento del pasado reciente, cumpliendo lo prometido por Foretic, se fotocopiaron, y era posible obtener sus imágenes escaneadas. ${ }^{29}$ De manera que las solicité: imagínese mi decepción tras comprobar que lo recibido era únicamente la carta de Bannisio, ${ }^{30}$ cuyo texto escrito en letra cursiva presenta muchas dificultades de lectura por hallarse múltiplemente horadado, sin las traducciones de las cartas de Elcano y de Punzorol que anexaba en origen. Mucho me temo que estas puedan haberse perdido para siempre. Espero poder verificar tal extremo personalmente en Dubrovnik en un futuro no muy lejano.

\section{De las Molucas al Adriático}

Gelcich, que desconocía el despacho diplomático de Bannisio hallado por Tadic, pensaba que fue un enviado de Ragusa a la corte imperial el que probablemente habría escrito y remitido al Senado de su ciudad una traducción de las cartas de Elcano y de Punzorol. ${ }^{31}$ Pero hoy sabemos que el responsable del envío fue Iacopo Bannisio, un clérigo nacido en 1466 en la isla de Curzola (Korčula), en Dalmacia, a apenas cien kilómetros de Ragusa. Educado en las universidades de Bolonia y Padua, estuvo al servicio de los Habsburgo desde 1493, primero del emperador Maximiliano I y luego de su nieto Carlos V, y también del Papado. Fue un diplomático y

27 Gavrilovic solo habla del «italiano» para designar la lengua usada en todos los ejemplares, pero más adelante comentaremos algunas de las palabras vénetas presentes en las copias hechas en Ragusa.

28 Gavrilovic, 1965, 604.

29 Agradezco a la archivera Tanja Ladišić, de los Archivos Estatales en Dubrovnik, sus eficientes gestiones en este sentido.

30 Trento, 6 de abril de 1523, Archivos Estatales en Dubrovnik, Croacia (AED), Diplomata et acta, 1523, n. 286.

31 Gelcich, 1889, 1-2. 
humanista notable, relacionado con personajes como Erasmo de Rotterdam o Alberto Durero. Lo que nos interesa aquí es que poco después de haber participado en la redacción del Edicto de Worms contra Lutero abandonó la cancillería imperial, y tras una breve estancia en la corte papal, se retiró a Trento en agosto de 1522, prestando de nuevo sus servicios al Emperador en el manejo de la correspondencia cancilleresca. ${ }^{32} \mathrm{Y}$ es allí donde le llegan las noticias del regreso de Juan Sebastián Elcano.

Bannisio, tanto por su origen dálmata como por el interés del Emperador en mostrar su buena voluntad hacia Ragusa, se había preocupado de mantener estrechas relaciones con esta república. ${ }^{33} \mathrm{~A}$ esto debemos añadir el interés de la corte imperial por hacer propaganda de la primera circunnavegación y de las reivindicaciones castellanas sobre las Molucas, que había llevado al mismísimo canciller Gattinara a entregar una copia de la carta de Elcano traducida al italiano a Gasparo Contarini, embajador de Venecia, tan pronto como en septiembre de $1522^{34}$; y aún hay alguna copia más de la de Elcano con aquella finalidad «divulgadora», ${ }^{35}$ tanto en italiano como en latín. ${ }^{36}$ No es de extrañar, por lo tanto, que desde Trento, el 6 de abril de 1523, Bannisio mencionara la Armada de la Especiería, entre otras cuestiones de política internacional, en una carta en italiano dirigida al Gobierno de la República de Ragusa. Dicho documento está signaturado actualmente como «Diplomata et Acta, 1523, n. 286». Como hemos dicho antes, para cuando Tadic publicó su traducción parcial en serbocroata de la

32 Rill, 1963. Gavrilovic, 1965, 595.

33 Gavrilovic, 1965, 595-596.

34 La historia de las distintas versiones conservadas del famoso aviso de Elcano ha sido analizada concienzudamente por Aguinagalde Olaizola, 2019, 145-176. De la traducción de Contarini se conservan dos versiones. La primera, al parecer más fiel al original, se debe a la mano de Alessandro Zorzi y se guarda en la Biblioteca Nazionale Centrale de Florencia, y fue publicada por Baldelli Boni, 1827, I: LXVI-LXVIII. La segunda, obra de Lorenzo Trevisán, secretario de Contarini, se halla en la Biblioteca Marciana de Venecia, Manoscritti Italiani, Classe XI [Códices Misceláneos], n. CXLIII [= 6676], ff. 14 a 17, y muestra ciertas variaciones que hacen pensar que es menos literal (Aguinagalde, 2019, 152). Esta última versión es la que publicó Guglielmo Berchet en la Raccolta di documenti e studi..., parte III, vol. I, 1892, 102-104; de esta es la traducción al castellano que se ha venido manejando en el mundo hispanohablante (Medina, 1920b, 291-294).

35 La versión en castellano del Archivo de Indias más parece una copia interna de trabajo del Consejo de Indias. AGI, Patronato, 48, r. 20.

36 La versión latina, obra de Benedictine Wolfgang Sedelius, predicador de la corte del duque Alberto V de Baviera, fue publicada por Schmeller, 1844, 269-273. Se custodia en la Bayerische Staatsbibliothek de Múnich, Catalogus codicum Latinorum Bibliothecae, n. 18.695. La otra italiana es una copia del dominico sajón Niklaus von Schönberg, secretario del cardenal Giulio de Médicis (luego papa Clemente VII), dada en Florencia a Benedetto Fantini, embajador de Ferrara, y que este remitió al duque Alfonso I d'Este. Harrisse, 1892, 713-714; Raccolta di documenti e studi..., parte V, vol. III, 1894, 23, n. 3; Castro et al., 2007, 1025; Elcano et al., 2012 [s. XVI], 10; Aguinagalde, 2019, 155. 
parte referida a la Armada de la Especiería, el papel ya estaba severamente deteriorado, lo que dificultaba sobremanera su lectura. Gavrilovic tradujo el texto de Tadic al inglés ${ }^{37}$ combinando y rectificando esta última versión con mi propia lectura de aquellos fragmentos que he podido descifrar. En español, quedaría como sigue:

Por cuanto el Reverendo Padre fray Joannes ${ }^{38}$ me dio a entender que sus Excelencias no están informados sobre el viaje a la India y las islas descubiertas por los españoles, donde crece la especiería, y cómo circunnavegaron la Tierra antes de que pudieran encontrarlos. ${ }^{39}$ De 5 barcos que navegaron con más de $400^{40}$ personas, sólo uno regresó con 18 hombres. Para que sus Excelencias puedan comprender esto mejor, adjunto les envío copias de los informes y cartas escritas a Su Majestad Cesárea ${ }^{41}$ de las cuales aprenderán cosas maravillosas de suma importancia. Esta nave que ha regresado ${ }^{42}$ ha traído, entre oro ${ }^{43}$ perlas, [ijoyas?] ${ }^{44}$ y especias, aproximadamente 300.000 ducados. ${ }^{45}$ La otra que se espera ${ }^{46}$ transporta otra tanta mercancía. ${ }^{47}$ Su Majestad Cesárea se encuentra ahora equipando 10 naves que envía a las Molucas; ${ }^{48}$ así se llaman esas Islas Benditas. ${ }^{49}$

Y tres líneas más adelante, en una frase que no recoge Gavrilovic, Bannisio asegura mandar «las cartas que fueron enviadas a la corte por la nave vizcaína», ${ }^{50}$ que claramente alude a la Victoria.

37 Gavrilovic, 1965, 597-598.

38 Gavrilovic reproduce la forma eslava del nombre, Iván Gucetic, aclarando que se trataba del embajador de Ragusa en Trento; lo que he podido leer en la primera página del documento es la forma latina, «Joannes Gocio», que es a quien se vuelve a mencionar aquí. AED, Diplomata et acta, 1523 , n. 286, f. 1 r.

39 Se refiere a los portugueses.

40 Si acaso, fueron 247. Mazón Serrano, 2020, 41.

41 Debemos suponer que la traducción de la carta de Elcano remitida por Bannisio es independiente de la de Gattinara entregada a Contarini, pues la copia que se hizo en Ragusa a partir de aquella, y que editó Gelcich $(1889,3)$, muestra tanto diferencias con la de Contarini como con la traducción latina.

42 La Victoria.

43 No leo los «lingotes» que vieron Tadic/Gavrilovic, solo «oro».

44 «Piedras preciosas» en Tadic/Gavrilovic. En esa zona falta mucho papel y no lo puedo leer con claridad.

45 Tanto Tadic/Gavrilovic como yo interpretamos la abreviatura de «m» que figura en superíndice tras «ccc» como multiplicador de «mil». La exageración es explicable, salvo errata, por el fin propagandístico de esta noticia: la cantidad real rondó los 23.000 ducados (Mazón Serrano, 2020, 214).

46 La Trinidad.

47 Leo en esta frase «L'altra che hè aspeta tene altra tanta roba»; en realidad la Trinidad era de mucho mayor porte que la Victoria, al menos un veinticinco por ciento más. Gavrilovic tradujo su versión como «Another ship, which is expected, carries the same amount of freight».

48 Se refiere a la armada de García Jofré de Loaysa, que partiría de La Coruña en 1525.

49 AED, Diplomata et acta, 1523, n. 286, f. 2v.

50 «... le lrē [lettere] che forno [por «furono»] expedite ala corte per la Naue Bischaina». AED, Diplomata et acta, 1523, n. 286, f. 2 v. 
CARTA DESDE LAS ISLAS DE LAS ESPECIAS: UNA NUEVA EDICIÓN DE LA MISIVA

\section{FIGURA 1}

CARTA DE IACOPO BANNISIO A LA REPÚBLICA DE RAGUSA (TRENTO, 6 DE ABRIL DE 1523)

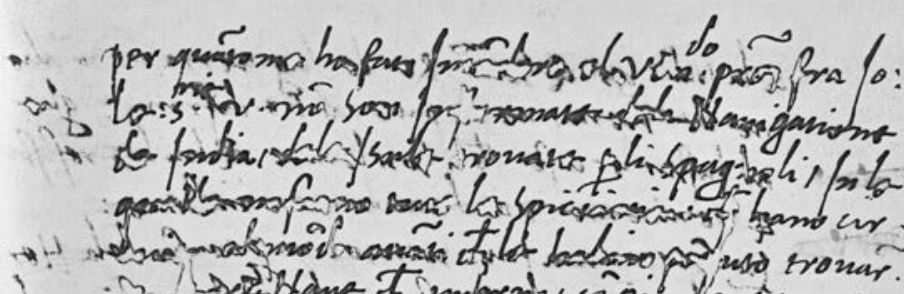

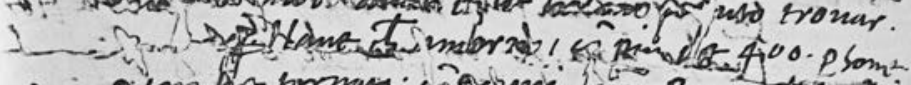

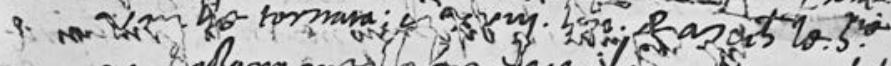

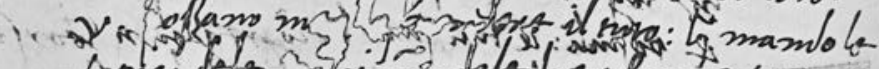

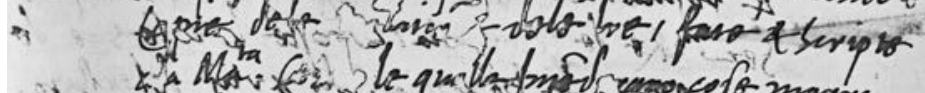

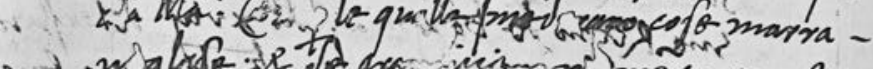

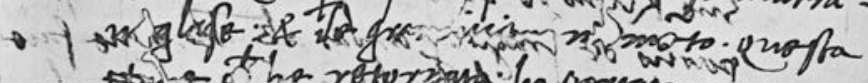

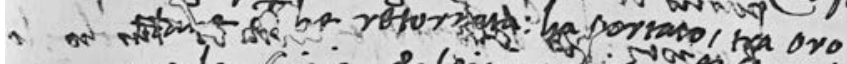

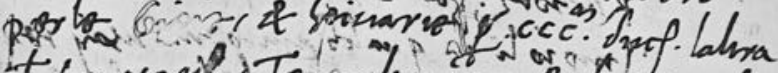

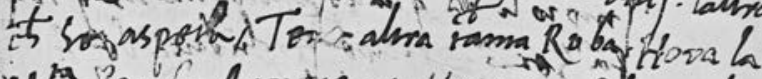

- walla

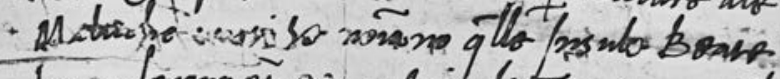

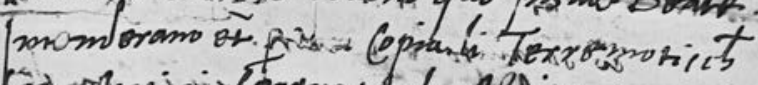

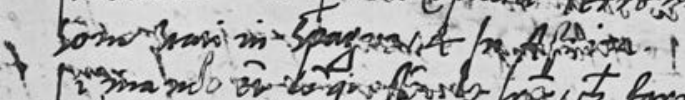

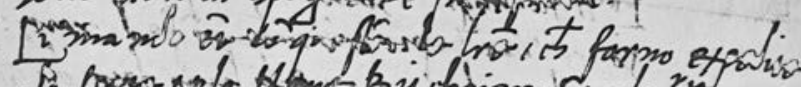

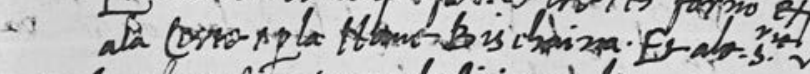

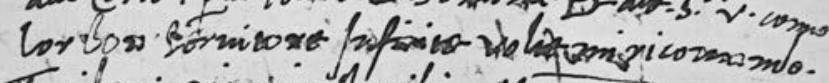

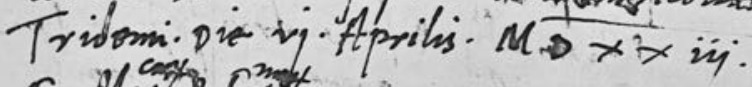
E. Mlag. \& Ex.D.

\section{Deolinseringsinger.

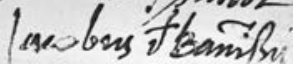

Fuente: Archivos Estatales en Dubrovnik, Diplomata et Acta, 1523, n. 286, f. 2v. 
No está de más explicar qué interés tenía una pequeña república de la costa del Adriático en guardar traslados de aquellas cartas en sus archivos. Conviene detenernos en este punto, siquiera con brevedad.

Ragusa era una república aristocrática que aglutinaba diversas poblaciones costeras dálmatas, y que se había independizado de Venecia a mediados del siglo XIV. Para sobrevivir tuvo que reconocerse subordinada a estados mucho más poderosos. ${ }^{51} \mathrm{Su}$ ubicación, en la frontera entre las civilizaciones cristiana e islámica, la ponía en una posición muy delicada; pero a la vez supo convertir dicha situación en una ventaja estratégica, desarrollando una estructura comercial y diplomática de alto nivel. Tuvo que transigir, por razones obvias, con convertirse en un estado tributario de la Sublime Puerta, pero a pesar del desprecio que Venecia le tenía por dicha sujeción, Ragusa conservó siempre su independencia de facto. Y ello, porque el primer interesado en que fuera autónoma era el propio Turco, al que convenía tener una plaza neutral con privilegios comerciales a un lado y a otro de la gran frontera religiosa que dividía el Mediterráneo en dos: así, ambos enemigos irreconciliables podían acceder a los mercados de la otra parte..$^{52}$ Paralelamente, Ragusa tuvo con los dominios de los Habsburgo una relación estrecha y de franca colaboración, que hundía sus raíces en los intercambios comerciales con la Corona de Aragón y sus posesiones italianas de la orilla occidental del Adriático, así como con mercaderes de la Corona de Castilla. ${ }^{53}$ Los raguseos gozaron durante los siglos XVI y XVII de una consideración especial en el Imperio español: ${ }^{54}$ no solo existió una floreciente comunidad de comerciantes raguseos en Cádiz, con presencia en el comercio con América, sino que encontramos marinos del mismo origen siendo pilotos de la carrera de Indias, ${ }^{55}$ y otros compatriotas suyos ocupando cargos en la administración hispana. ${ }^{56}$ Así pues, Ragusa basó buena parte de su prosperidad en el juego de equilibrios entre imperios, y gracias también al apoyo de unos y otros pudo garantizar la independencia frente a su principal amenaza y competidor comercial: la cercanísima y Serenísima

51 Fue así desde los orígenes medievales del estado raguseo. Stuard, 1992.

52 Kunčević, 2013, 91-121.

53 También está documentada la presencia en Ragusa de comerciantes guipuzcoanos y vizcaínos. Aguinagalde, 2019, 158, n. 45.

54 Gavrilovic, 1962, 22-29.

55 Hace años tuve ocasión de describir la aprobación y el examen como piloto de la carrera de Indias del raguseo Juan Andrés Esmaili, a finales del siglo XVII. AGI, Contratación, 5782, n. 53 y n. 83.

56 Polić Bobić, 1991, 112. 
República de San Marcos. ${ }^{57}$ En este contexto, el tráfico de noticias («de datos», diríamos hoy) era parte vital de la política exterior ragusea, y las cartas de Elcano y de Punzorol constituían una información de primer orden sobre la pugna por el control del comercio de las especias entre las potencias ibéricas, lo que sin duda interesaría, entre muchos otros, a los otomanos.

\section{Consideraciones sobre la carta original de Punzorol y sus copias}

Ni en la seriamente dañada traducción de Bannisio ${ }^{58}$ ni en la copia ragusea editada por Gelcich figura el destinatario de la carta de Punzorol; tan solo se habla de un «noble señor» al que se dirige con el tratamiento de «vuestra señoría». Es una pena que desconozcamos quién era ese personaje, pues evidentemente sería una pista de primer orden para seguir el rastro del original en los archivos españoles. Luigi Avonto aventuró una hipótesis ya desechada por Gelcich: ${ }^{59}$ que ese «noble señor» fuera Pedro Mártir de Anglería. ¿Quién mejor, argumentaba Avonto, que este cronista tan interesado en el proyecto magallánico de controlar el tráfico de las especias? Datos a favor de su propuesta son que Anglería había visto reforzada su posición en la corte después de la llegada de Carlos I al trono, que le valdría puestos en la Junta (al poco Consejo) de Indias, así como la dignidad de abad de Jamaica; y que estaba siempre pendiente de las maravillas que llegaban de ultramar en las naos descubridoras, como ese clavo que trajo la nao Victoria, del que alguna muestra remitió al mismísimo Papa ${ }^{60}$ Ahora bien, había muchos más personajes a los que podía dirigirse Punzorol como «vuestra señoría» y «noble señor». En última instancia, Avonto fía toda la fuerza de su hipótesis en que la carta original estuviera escrita en italiano (obviemos qué dialecto pudo haberse empleado), y en que, por consiguiente, su lector también lo fuera ${ }^{61}$ En este momento es necesario traer a colación que la copia escrita para las autoridades de Ragusa lleva al final una acotación que reza: «Io l'o translatata io medesimo miglio ho possuto...».

Toribio Medina interpretó «translatata» como «traducida», bajo el supuesto (tomado de Gelcich) de que la fuente era la carta escrita en castellano

57 Madunić, 2013, 341-342.

58 Tadic, 1931, 239. Gavrilovic, 1965, 607.

59 Gelcich, 1889, 10.

60 Mártir de Anglería, 1944 [1550], década V, lib. VII, cap. VI, 437. Salas, 1986, 34-36.

61 Avonto, 1992, 44-45. 
por Punzorol. Cierto que tanto en italiano («traslatare» / «translatare» $)^{62}$ como en castellano («trasladar») ${ }^{63}$ ese verbo significa, entre otras cosas, «traducir»; no es menos cierto que en español también significa «copiar», mientras que en véneto no he conseguido atestiguar ninguna de esas dos acepciones. ${ }^{64}$ Pero dado que en todas estas lenguas romances el vocablo en cuestión deriva del latín «trānsferō», que incluye entre sus sentidos tanto «traducir» como «copiar», ${ }^{65}$ la frase podría querer decir tanto «la he traducido yo mismo lo mejor que he podido» como «la he copiado...». ¿Tiene sentido hablar de traducción cuando los de Ragusa partían de la versión italiana de Bannisio? En conclusión, no parece que pueda utilizarse esta acotación del copista como prueba de que la carta original de Punzorol estuviera escrita en un idioma o en otro. Aun así, en mi opinión, lo más verosímil es que el maestre genovés utilizara el castellano, pues del tema y del tono de la carta puede deducirse que el desconocido destinatario era un oficial regio o un cortesano de cierta posición y con influencia en los asuntos de Indias, y tales eran mayoritariamente naturales de la Corona de Castilla. No es problemático suponer que conocía lo suficientemente bien la lengua de Nebrija como para escribirla - y si no, no le faltarían compañeros que le auxiliaran-. A este respecto, existen dos cartas en castellano firmadas por Juan Bautista y el piloto León Pancado los días 20 y 25 de octubre de 1525 durante su cautiverio en Mozambique; sin embargo, sabemos que no las escribieron ellos mismos, sino que hicieron uso de los servicios de algún escribano portugués. ${ }^{66}$

Una objeción más se me ocurre a que el receptor de la misiva fuera Pedro Mártir: a diferencia de todos los testimonios presenciales, incluido el de nuestro maestre, aquel cronista no identifica la avería de la Trinidad como un agujero enorme en la quilla, sino como una consecuencia de estar «carcomida, corroída, podrida y tan agujereada por los gusanos que en

62 Tesoro della lingua Italiana delle Origine, 1997, s. v. «traslatare». Treccani, s/f, s. v. «traslatare». Disponible en: http://www.treccani.it/vocabolario/traslatare/ [Consultado: 18/06/2020].

63 RAE, 2014, s. v. «trasladar» [Consultado: 18/06/2020].

64 Boerio, 1867, 763, s. v. «traslatàr». Contarini, 1850, 328.

65 Valbuena, 1808, 765, s. v. «transfěro». De Miguel y Marqués de Morante, 1867, 941, s. v «transfěro».

66 Estas cartas ya han sido citadas antes (ANTT, PT/TT/GAV/15/10/34; ANTT, PT/TT/ GAV/17/6/24). Véase el análisis de Mazón Serrano, disponible en: https://www.rutaelcano.com/cartasde-mozambique [Consultado: 16/03/2021]. Otro ilustre tripulante de la Trinidad, el capitán Gómez de Espinosa, había escrito una carta en su prisión en la India también en 1525, dictándosela a un escribano cuyos portuguesismos le delatan. En AGI, Indiferente General, 1528, n. 2. Disponible en: http://pares. mcu.es/ParesBusquedas20/catalogo/description/304066?nm [Consultado: 25/06/2020]. 
italiano se llaman bisas y en español broma, que por sus costados y por el fondo pasaba el agua como por una criba». ${ }^{67}$ Recuerda más al estado de la Victoria tal y como lo describió Elcano ${ }^{68}$ que al episodio de la rotura del casco relatado por Punzorol, lo que no deja de ser extraño si Pedro Mártir hubiera conocido su versión.

Volviendo nuestra atención a la apostilla final que mencionábamos, en ella encontramos, quizá, la clave del contexto en el que se hizo la copia: «Io l'o translatata io medesimo miglio ho possuto, pero doue e la linea di sopra li non lo intesa molto bene, et per fratt[amente] non posso imformarmine. Se importerà ve lo riscriverò». Es decir, «La he copiado yo mismo lo mejor que he podido, pero donde está la línea de arriba no lo entiendo muy bien, y no puedo informarme por la prisa excesiva. Si es importante, lo reescribiré». En efecto, hay una frase a la que sobrevuela una línea para señalar que el copista no ha sabido comprenderla: «[...] per lo Dalín, doue Andrea Nino fa le naue [...]». En mi traducción: «[...] para el Dalín [Darién], donde Andrés Niño hizo las naves [...]».

Gelcich había leído en esa misma frase «per lo dahu dove andrea riuso fa le nave», y si bien no supo leer correctamente ni el apellido del marino Andrés Niño («riuso» por «Nino») ni el topónimo («dahu» por «Dalín»), sí interpretó bien que este último se refería en realidad a «Darién», en la costa de Panamá. Pero volviendo a la cuestión que nos ocupa ahora, decía Gelcich sobre esta cita que «dado que estas palabras tienen un significado puramente español, se debe suponer que es una traducción del original en español». ${ }^{69}$ Insisto en que todo apunta a que la copia realizada en Ragusa se hizo a partir de la traducción al italiano enviada por Bannisio. Independientemente de que pensemos, como también lo hacía Gavrilovic, que la carta original de Punzorol estuviera escrita en castellano, ${ }^{70}$ cualquier súbdito español mínimamente familiarizado con los descubrimientos en el Nuevo Mundo podría haber informado de la expedición de Andrés Niño de 1519, y de las naos que pensaba construir en la tierra del Darién para ir en busca del Maluco. El copista ni siquiera transliteró bien este último topónimo, pero es que cometió otros errores más groseros: en la carta de Elcano leyó

67 Mártir de Anglería, 1944 [1550], década V, lib. VII, cap. VI, 437.

68 Carta de Juan Sebastián Elcano dando noticia de la primera vuelta al mundo, Sanlúcar de Barrameda, 6 de septiembre de 1522, AGI, Patronato, 48, r. 20, f. 2r. Disponible en: http://pares.mcu.es/ ParesBusquedas20/catalogo/show/7343174?nm [Consultado: 25/06/2020].

69 «Da diese Worte rein spanische Bedeutung haben, so muss vorausgesetzt werden, dass es sich um eine Uebersetzung aus dem spanischen Original handelt». Gelcich, 1889, 2.

70 Gavrilovic, 1965, 601. 
en la firma del ilustre guetariense «de Ghogni»; y dice que los europeos que volvieron en la Victoria fueron «xviiii», y no la cifra correcta, «xviii», como se leía en la documentación remitida por Bannisio. ${ }^{71} \mathrm{Si}$, como parece, las copias en Ragusa se confeccionaron a partir de la traducción italiana y no de los originales castellanos, estos fallos no son debidos a una mala comprensión del idioma, o a una mala lectura de la letra gótica empleada en Castilla y Portugal por entonces (que, por otra parte, es dudoso que fuera la propia de un maestre genovés). Estamos ante la combinación de algunos de estos posibles factores: falta de pericia del escribano para leer la letra cursiva de la traducción de Bannisio; dificultades físicas en la lectura derivada del deterioro del documento, que es posible que se iniciara en una época muy temprana; y déficit de conocimientos sobre los descubrimientos geográficos castellanos.

\section{La edición de Gelcich y la traducción de Medina, revisadas}

El pliego que contiene las copias en buen estado de las cartas de Elcano y Punzorol se custodia en los Archivos Estatales en Dubrovnik, bajo la signatura «HR-DADU-7-3-6, Diplomata et acta, siglo XVI, sv. 1, n. 27». En el folio 2 vuelto de dicho pliego hay una anotación de archivo que reza: «N. ${ }^{\circ} 27 /$ an. $1521 / \mathrm{F}^{\circ} \mathrm{I} »$. La letra empleada en ambos documentos es la misma, una limpia y clara humanística con alguna reminiscencia gótica; la lengua empleada muestra particularidades del véneto que se manejaba por entonces en la cancillería de aquel pequeño estado costero. En sus folios 1 vuelto y 2 recto se encuentra la carta de Punzorol, identificada por una letra «B» (la de Elcano es la «A»).

La transcripción de Gelcich cambia algunos caracteres del documento para adaptar la lectura al italiano normativo de su época, pero, en puridad, su lectura es acertada casi siempre, y no altera el sentido, salvo en un par de ocasiones relevantes que he señalado ya, y que aclaro de nuevo en las notas a mi edición. De esta publicación efectuó su traducción al castellano -en líneas generales también correcta- el erudito chileno José Toribio Medina Zavala, en su magna obra sobre el descubrimiento europeo del océano Pacífico. $^{72}$

71 Carta de Iacopo Bannisio a la República de Ragusa, Trento, 6 de abril de 1523, AED, Diplomata et acta, 1523, n. 286, f. 2v. Gavrilovic, 1965, 605.

72 Gelcich, 1889, 7-8. Medina, 1920a, 93-94. 
¿Por qué realizar ahora una nueva edición de esta rara carta? ¿Qué puede aportar?

En primer lugar, siempre merece la pena revisitar las fuentes, y no conformarse con lo que nos han transmitido trabajos anteriores, por muy rigurosos que sean (como es el caso). Y no por ajustar su lectura literal a una u otra normativa de transcripción de manuscritos históricos, ${ }^{73}$ sino porque el estudio de los caracteres externos e internos del documento siempre puede aportar un granito más de conocimiento que ha pasado desapercibido. Verbigracia, podemos responder a una pregunta tan elemental como si la copia es coetánea del original, o muy posterior, como fruto de un somero análisis paleográfico. ${ }^{74} \mathrm{He}$ apuntado más arriba que la letra utilizada es ya humanística; sin embargo, muestra particularidades de la gótica tales como la «d» uncial, la conjunción copulativa «et», la «s» de doble curva tan pronunciada, la indefinición «u»/ «V», y una serie de elementos que, en un ámbito cultural italiano, nos sitúan a comienzos del siglo XVI. Esto es, que podemos afirmar, sin demasiado temor a equivocarnos, que la copia hecha en Ragusa se elaboró no mucho después de la recepción de la traducción italiana remitida por Iacopo Bannisio en 1523. Incluso procede preguntarnos si no se emprendió tal tarea porque ya empezaban a deteriorarse los papeles de Bannisio por mor de la acción corrosiva de la tinta (tanto por exceso de óxido de hierro en esta, como por el propio $\mathrm{pH}$ del papel), proceso catalizado por las condiciones de alta humedad tan comunes en las ciudades costeras.

Otra cuestión que requiere nuestra atención es la idiomática. La carta es perfectamente inteligible para un conocedor del italiano actual, pero no hay que dejar de señalar las particularidades léxicas vénetas que pueblan el texto. Tampoco pueden desdeñarse distintas acepciones, tanto en italiano antiguo como en véneto, que varían de forma sustancial la interpretación de un episodio fundamental de la expedición. Así, cuando se nombra un triunvirato para dirigir la Armada de la Especiería, Juan Bautista relata cómo lo hicieron «gouernator dell'armata». Toribio Medina, quizás en su único error, aventura la traducción «general de la armada», lo que puede dar lugar a equívocos sobre la posición de poder relativo del maestre; en realidad, en italiano «governator» («governadór» / «goernadór» en véneto) significaba,

73 Aquí me he ceñido a una combinación de la obra de Tognetti, 1982, y a las normas de transcripción paleográfica acordadas por el Grupo de Trabajo de Catalogación de Manuscritos, 2001.

74 Debo agradecer a la Dra. D. ${ }^{a}$ Reyes Rojas García, del Archivo General de Indias, su ayuda en cuestiones paleográficas, en especial en los pasajes de lectura más dudosa. 
en un contexto náutico, el que regía la embarcación, maniobrando con el timón. En todo caso, en los documentos castellanos coetáneos que narran los mismos hechos se alude a aquel triunvirato como «gobernadores», dejando en pie de igualdad a Punzorol, a Elcano y a Gómez de Espinosa. ${ }^{75}$ Dicho lo cual, ni que decir tiene que fío en estudiosos más versados que yo en el italiano y el véneto del siglo XVI para mejorar la traducción que modestamente ofrezco en estas páginas.

Finalmente, en cuanto al contenido de esta carta, que por lo poco que podemos saber es esencialmente el mismo tanto en la traducción enviada por Bannisio ${ }^{76}$ como en la copia ragusea editada por Gelcich, es admirable cómo en tan breves líneas nuestro maestre es capaz de condensar lo sucedido en el viaje desde la muerte del capitán general Magallanes en la batalla de Mactán: el nombramiento de nuevos capitanes, la llegada al Maluco, la buena acogida del rey de Tidore, las innumerables riquezas en especias de aquellas islas, la avería de la Trinidad y la partida de la Victoria, la encomienda de su hijo al desconocido destinatario de la epístola... ¡Y el envío de unos papagayos que añadía como obsequio! Pero mejor dejar hablar al propio Juan Bautista de Punzorol.

Recibido, 31 de julio de 2020 Segunda versión, 19 de octubre de 2020 Aceptado, 17 de noviembre de 2020

75 «Paces del Maluco», nao Victoria, 1521, AGI, Indiferente, 1528, n. 1, f. 2r.

76 En la traducción al serbocroata resumida en la obra de Tadic, este incluyó solo unas pocas citas de la versión de Bannisio. Gavrilovic, 1965, 607. 
FigURA 2

CARTA DE JUAN BAUTISTA DE PUNZOROL, ISLA DE TIDORE,

21 DE DICIEMBRE DE 1521
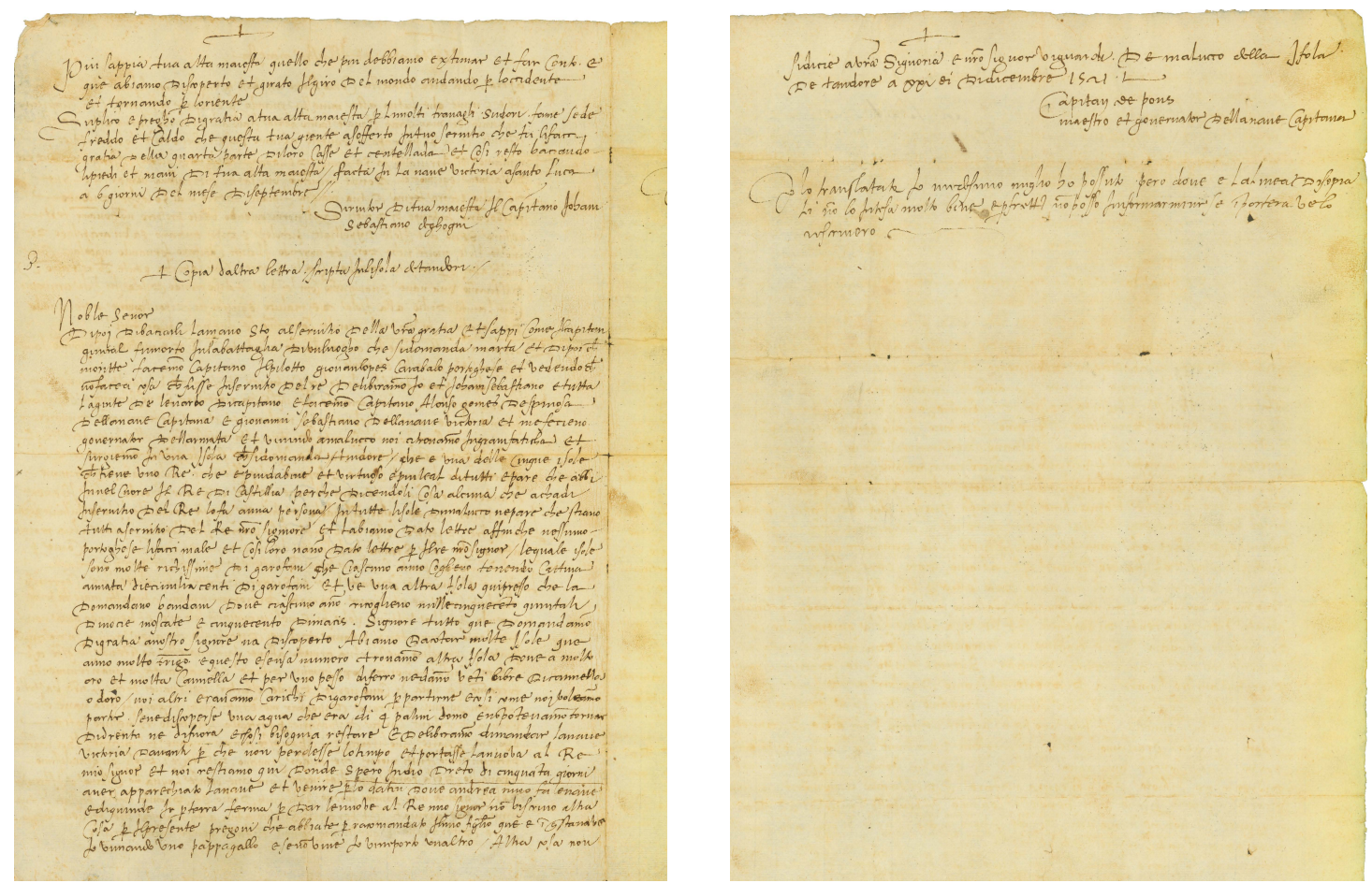
B.

[Cruz $]$ Copia de otra carta escrita en la isla de Tambri. ${ }^{77}$

\section{Noble Señor:}

Después de besarle la mano, estoy al servicio de vuestra gracia. Y sabed cómo el capitán general fue muerto en la batalla de un lugar llamado $\mathrm{Marta}^{78}$. Y después de que murió, hicimos Capitán al piloto Juan Lopes Carabalo, ${ }^{79}$ portugués. $\mathrm{Y}$ viendo que no hacía cosa que fuese en servicio del Rey, deliberamos yo y Juan Sebastián y toda la gente de quitarlo de capitán, e hicimos Capitán a Alonso ${ }^{80}$ Gómez de Espinosa de la nao
B. ${ }^{94}$

$[\mathrm{Cruz}]^{94}$ Copia d'altra letra scripta in l'isola de Tambri. ${ }^{77}$

\section{Noble Senor:}

Dipoi di baciarli la mano sto al seruitio della Vostra Gratia. Et Sappi come il capitan / giniral fu morto in la battaglia di vn luogho che si domanda Marta. ${ }^{78}$ Et dipoi che / moritte, facemmo Capitano il pilotto Giouan Lopes Carabalo, portoghese. Et vedendo che / non facea ${ }^{95}$ cosa che fusse in seruitio del Re, delibirammo Io et Joham Sebastiano e tutta / la ginte de leuarlo di capitano, et facemmo Capitano Alonso ${ }^{80}$
Noble senor:

Di poi di baciarli la mano sto al servitio della vostra gratia, et sappi come il capitan general fu morto in la battaglia di un luogo che si domanda marta. Et di poi che moritte facemmo capitano il piloto Giovan Lopes Carbalo portoghese, et vedendo che non faceva cosa che fosse in servitio del re deliberammo io et Johann Sebastiano e tutta la gente di levarlo di Capitano et facemmo Capitano Alonso Gomes de spi-
Noble señor.-

Después de besarle la mano, quedo al servicio de Vuestra Gracia, y ha de saber cómo el Capitán General fué muerto en una batalla que tuvo lugar en un sitio que se llama Marta (sic). Y después de su muerte hicimos capitán al piloto Juan López Caravalo, portugués, y viendo que no hacía cosa que fuese en servicio del Rey, resolvimos yo y Juan Sebastián [del Cano] y toda la gente de quitarle el mando, e hicimos capitán a Alonso (sic) Gómez

77 Sic por Tidore.

78 Sic por Mactán.

79 Se refiere a João Lopes Carvalho, que había empezado el viaje al Maluco como piloto de la nao Concepción.

80 Es inverosímil que Juan Bautista errara en el nombre del capitán de la Trinidad, que era «Gonzalo»: ha de tratarse de un error de copia.

$94 \mathrm{Al}$ margen.

95 Sic por «faceva». 
capitana, y a Juan Sebastián de la nao Victoria, y a mí me hicieron gobernador [o piloto $]^{81}$ de la Armada. Y viniendo al Maluco, nos encontramos en gran fatiga. $Y$ fondeamos $^{82}$ en una isla que se llama Tindore, ${ }^{83}$ que es una de las cinco islas, que tiene un rey que es el mejor, virtuoso y más leal de todos, y parece que tuviera en el corazón al Rey de Castilla, porque diciéndole cualquier cosa que acaece en servicio del Rey, la pone en obra personalmente. ${ }^{84}$ En todas las islas del Maluco parece que están
Gomes Despinosa / della naue Capitana, e Giouanni Sebastiano della naue Victoria, et me fecieno $^{96}$ / gouernator dell'armata. Et vinindo a Malucco, noi ci trouammo in gram faticha, et / surgiemmo ${ }^{82}$ in vna isola che si domanda Tindore, ${ }^{83}$ che è vna delle cinque isole / che tiene vno Re, che è più dabine ${ }^{97}$ et virtuoso e più leal di tutti, e pare che abbi / in nel cuore il Re di Castillia, perche dicendoli cosa alcuna che achadi ${ }^{98} /$ in seruitio del Re, lo fa anna ${ }^{84}$ persona. In tutte l'isole di Malucco ne nosa della nave capitana, et Giovanni Sebastiano della nave Victoria, et me feciero governator dell'armata. Et viniendo a malucco noi ritrovammo in gran faticha et surgiemmo in una isola che si domanda tindore, che è una delle cinque isole che tiene uno re che è più da bene et virtuoso e più leal di tutti $\mathrm{e}$ pare che abbi in nel cuore il re di Castillia, perche dicendoli cosa alcuna che achadi in servitio del re lo fa anna persona. In tutte le isole di malucco ne pare che stiano tutti a servitio del re nostro de Espinosa de la nave capitana y a Juan Sebastián de la nave Victoria y a mí hicieron general $^{107}$ de la armada. Y llegando a Maluco nos hallamos en gran fatiga y surgimos en una isla que se llama Tindore (sic) que es una de las cinco islas que posee cierto rey, que es el mejor, virtuoso y más leal de todos, y parece tener en mucho afecto al Rey de Castilla, porque en proponiéndole cualquiera cosa que ataña al servicio del Rey, la ejecuta en persona. En las islas de Maluco me parece que todos se hallan al servicio del

81 Tesoro della lingua Italiana delle Origine, 1997, s. v. «governatore»: «1 [Mar.] Chi regge e manovra il timone (di un'imbarcazione)». Boerio, 1867, 312, s. v. «governatòr»: «governatòr de nave appellavasi il Patrizio Veneto preposto a comandare una pubblica nave...».

82 En su traducción, Gelcich (1889, 7, n . 5) cita el español «surgir» en su acepción de «dar fondo» o «anclar»; pero también en italiano tiene desde antiguo ese mismo sentido (Tesoro della lingua Italiana delle Origine, 1997, s. v. «surgire»/«sórgere»).

83 Sic por Tidore.

84 Dudo entre «anna» (como lee Gelcich) o «a una»; en cualquier caso, creo que la interpretación de Gelcich y la traducción de Medina, «en persona», es correcta.

96 Lo supongo conjugación del verbo «fare» (italiano) o «far» (véneto).

97 Parece corresponder al véneto «dabén», en italiano actual «dabbene», que significa «de bien». Traduttore veneto. Disponible en: http://www.linguaveneta.net/strumenti/traduttore/ [Consultado: 15/06/2020].

98 Lo supongo emparentado con el italiano actual «accadere», esto es, «suceder».

107 Esta es mi mayor discrepancia con la traducción de Medina, como he justificado antes. Véase nota 81. 
todos al servicio del Rey nuestro señor, y les hemos dado cartas para que ningún portugués les haga mal, y del mismo modo ellos nos han dado cartas para el Rey nuestro señor. ${ }^{85}$ Las cuales islas son riquísimas en clavo, que cada año recolectan, teniendo una añada mala, diez mil cien $^{86}$ de clavo. Y hay otra isla cerca, que la llaman Bandam, ${ }^{87}$ donde cada año recogen mil quinientos quintales de nuez moscada, y quinientos de macis. Señor, todo lo que pedimos por gracia a Nuestro Señor se ha descubierto. Hemos de contar muchas islas que tienen mucho trigo, y esto es sin número. $\mathrm{Y}$ encontramos otra isla donde pare che stiano / tutti a seruitio del Re nostro Signiore, et l'abiamo dato lettre affinché nessuno / portoghese li facci male, et così loro n'ano dato lettre per il Re nostro Signor. Le quale isole / sono molte richissime di garofani, che ciascuno anno coglieno, tenendo cattiua / annata, dieci milia centi ${ }^{86} \mathrm{di}$ garofani. Et v'è vna altra isola qui presso che la / domandano Bandam, doue ciascuno anno ricoglieno mille cinquecento quintali / di nocie moscate, et cinquecento di macis. Signore, tutto che domandammo / di gratia a nostro signore n'a discoperto. Abiamo da contar molte isole que / anno molto
Signore, et l'abiamo dato lettre affinchè nessuno porto ghese li facci male. Et cosi loro ne anno dato lettre per il re nostro signor, le quali isole sono molte richissime di garofani, che ciascuno anno coglieno, tenendo cattiva annata dieci milia centi di garofani. Et v' è un'altra isola qui presso che la domandano bandam dove ciascuno anno ricoglieno mille cinquecento quintali di nocie moscate et cinquecento di macis. Signore, tutto que domandammo di gratia a nostro Signore n'a discoperto. Abiamo da contar molte isole que anno molto trigo e questo è senza numero. Et trovammo altra isola dove a molto oro et
Rey nuestro señor, y le hemos dado cartas a intento de que ningún portugués le haga daño. Y él también nos ha dado carta para el Rey, nuestro señor. Cuyas islas son riquísimas de clavo, que se cosecha cada año, teniendo de cosecha al año diez (?) (quintales) de clavo. Y hay otra isla cercana, que se llama Bandam, en la que anualmente se cosechan mil quinientos quintales de nuez moscada y de macis. Señor, todo lo que por gracia pedimos a Nuestro Señor se ha descubierto. Habremos también de contar muchas islas que todos los años producen mucho trigo, $\mathrm{y}$ éstas son sin número. Y descubrimos otra isla que tiene

85 Este intercambio diplomático puede seguirse en las citadas «Paces del Maluco», AGI, Indiferente General, 1528, n. 1.

86 «Cien» es en italiano «cento», y no me consta la forma «centi». ¿Alude a otra unidad de medida? ¿O se refiere a quintales, como de los que se habla a continuación?

87 Acaso se refiera a la que el conocido como «Derrotero de Francisco Albo» (el piloto de la Victoria bajo el mando de Elcano) llama «Bachián» (Bacan). AGI, Patronato, 34, r. 5, f. 16v. Disponible en: http://pares.mcu.es/ParesBusquedas20/catalogo/show/122214?nm [Consultado: 08/07/2020]. Hay una isla llamada Banda en el entorno, pero no parece que pueda decirse que esté cerca, pues se halla a unos $650 \mathrm{~km}$ al sursudeste de las Molucas. 
hay mucho oro y mucha canela, y por un peso ${ }^{88}$ de hierro nos dan veinte libras de canela o de oro. El resto de nosotros estábamos cargados de clavo para irnos, y así como quisimos partir, se descubrió un agua ${ }^{89}$ que era de 4 palmos de hombre, y no podíamos corregirla ni por dentro ni por fuera, y por lo tanto es preciso quedarse. $\mathrm{Y}$ decidimos tras deliberar mandar la Victoria adelante, porque no perdiese el tiempo y llevase la noticia al Rey mi señor. Y nosotros permanecemos aquí, donde espero en Dios haber apare- trigo, e questo è sensa numero. Et trouammo altra isola doue a molto / oro et molta cannella, et per vno pesso di ferro ne danno venti libre di cannella / o d'oro. Noi altri erauammo carichi di garofani per partirne, e così come noi voleammo / partir, se ne discoperse vna agua ${ }^{89}$ che era di 4 palmi d'òmo, ${ }^{99} \mathrm{e}$ non poteuammo tornar ${ }^{100} / \mathrm{di}$ drento ne di fuora, e chosì bisognia restare. Et deliberammo di mandar la naue / Victoria dauanti perche non perdesse lo timpo ${ }^{101}$ et portasse la nuova al Re / mio molta cannella, et per uno pesso di ferro ne danno venti libre di cannella o d'oro. Noi altri eravamo carichi di garofani per partirne e così come noi voleximo partir, se ne discoperse una aqua che era di 4 palmi d'omo e non potevamo tornar di drento ne di fuora, e chosi bisognia restare. Et deliberammo di mandar la nave Victoria davanti perche non perdesse lo tempo et portasse la nuova al re mio signor, et noi restiamo qui donde spero in dio drento di cinquanta giorni aver apparecchiato la nave et mucho oro y mucha canela, y por un peso de hierro nos dan veinte libras de canela o de oro. Nosotros habíamos cargado el clavo para partirnos, y cuando quisimos hacerlo, se descubrió una vía de agua, que era de cuatro palmos y no podíamos remediarla por dentro ni por fuera, y así nos fué preciso quedarnos. Y resolvimos mandar adelante la nave Victoria, para que no perdiese tiempo y llevase las nuevas al Rey mi señor, y nosotros quedamos aquí, donde, espero en Dios, haber alistado la nave dentro de cincuenta

88 No he podido averiguar el valor de esa unidad de medida. Acaso se refiera a que por una unidad de peso de hierro (la libra de la que se habla a continuación, que en Castilla equivalía a $0,460 \mathrm{~kg}$ ), obtenían veinte de oro o de canela. O, como interpreta Gelcich (1889, 8 , n. 4), «cierto peso».

89 Como en italiano, en español «agua» también tiene la acepción de «rotura, grieta o agujero por donde entra en la embarcación el agua en que ella flota». RAE, 2014, s.v. «agua», acepción n. 7.

99 En dialecto véneto, «òmo» significa «hombre». Traduttore veneto. Disponible en: http://www.linguaveneta.net/strumenti/traduttore/ [Consultado: 15/06/2020].

100 Por el contexto de la frase, aquí debe de decir «corregir» (y así lo recojo en mi traducción), «reparar», o «remediar», como traduce Medina. No es el caso del verbo «tornare», o al menos no he encontrado una acepción tal ni en el italiano actual ni en el del siglo XVI, y lo mismo en el véneto. ¿Quizá se trata de «tornire», que significa «tornear» o «pulir»? ¿O más bien una forma dialectal que se escapa a mi conocimiento?

101 Sic por «tènpo» en dialecto véneto, o «tempo» en italiano actual. Traduttore veneto. Disponible en: http://www.lingua veneta.net/strumenti/traduttore/ [Consultado: 15/06/2020]. 
jado la nave dentro de cincuenta días, y partir para el Dalín, ${ }^{90}$ donde Andrés Niño hizo las naves, y luego ir por Tierra Firme para dar las nuevas al Rey mi señor. No escribo más por el momento; os ruego que tengáis por recomendado a mi hijo, que se encuentra en esta nao. Os envío un papagayo, y, si no sobrevive, yo le llevo otro. No hay más ${ }^{1 \mathrm{v}}$ que decir a vuestra señoría, y Nuestro Señor os guarde. De Maluco, desde la isla de Tandore, ${ }^{91}$ a xxi de diciembre de 1521 .
Signor. Et noi restiamo qui, donde spero in Dio drento di cinquanta giorni / auer apparechiato la naue, et venire per lo Dalín, ${ }^{102}$ doue Andrea Nino fa le naue, ${ }^{103} /$ et di quinde ir per Terra Ferma per dar le nuove al Re mio Signor. Non vi scriuo altra / cosa per il presente; prego ui che abbiate per racomandato il mio figlio, que è in questa nave. / Io vi mando vno pappagallo, e, se non viue, io vi ne porto vn'altro. Altra cosa non $/{ }^{1 \mathrm{v}}$ si dicie a vostra Signoria, e nostro Signor vi guardi. De Malucco, della isola de Tandore, ${ }^{91}$ a xxi di Dicembre 1521. venire per lo dahu dove andrea riuso ${ }^{105}$ fa le nave et di quinde in per terra ferma per dar le nuove al re mio Signor. Non vi scrivo altra cosa per il presente; pregovi che abbiate per raccomandato il mio figlio che è in questa nave. Jo vi mando uno pappagallo è se non vive io ve ne porto un'altro. Altra cosa non si dice a vostra Signoria, et nostro Signor vi guardi.

De Malucco della isola di Tandore a XXI di Dicembre 1521. días y venir por el Darién, donde Andrés Niño hizo las naves, y de allí por tierra firme para dar las nuevas al Rey mi señor. No digo más por la presente, rogándoos que hayáis por encomendado al hijo mío que va en esta nave. Yo os envío un papagayo, y por si se muriere, yo llevo otro. No hay más que decir a Vuestra Señoría, y el Señor os guarde. De Maluco, de la isla de Tandore (sic) a XXI de diciembre 1521.-

90 Sic por Darién

91 Sic por Tidore.

102 Gelcich $(1889,8$, n. 6) lee «Dahu», si bien interpreta correctamente que se refiere al Darién. Se equivoca, en cambio, cuando dice que le «gustaría leer: per lo darien dove si arrimará la nave», pero es que su transcripción «per lo dahu dove andrea riuso fa le nave» es errónea; parece que desconocía quién era Andrés Niño.

103 Las palabras «per lo Dalín, doue Andrea Nino fa le naue» tienen una línea encima, que es a la que se refiere la anotación final del documento: «doue e la linea di sopra / li non lo intesa molto bene» («pero donde está la línea de arriba no lo entiendo muy bien»).

105 Lectura errónea tanto en «Dahu» (que leo «Dalín», por «Darién») como en «riuso» por «Nino», el apellido del explorador Andrés Niño. 
Capitán de Pons, ${ }^{92}$

Maestre e piloto de la nao capitana.

La he copiado ${ }^{93}$ yo mismo lo mejor que he podido, pero donde está la línea de arriba no lo entiendo muy bien, y no puedo informarme por la excesiva prisa. Si fuera importante, lo reescribiré.
Capitan de Pons, ${ }^{92}$

Maestro et gouernator della naue Capitana.

Io l'o translatata io medesimo miglio ho possuto, pero doue e la linea di sopra / li non lo intesa molto bene, et per fratt[a]mente ${ }^{104}$ non posso imformarmine. Se importerà ve lo / riscriverò.
Capitan de pons

maestro et governator della nave capitana

, Ho translatato io medesimo miglio ho possuto, però dove e la linea de sopra, lì non l'ò intesa molto bene e perfettamente non posso informarmene. Se importerà ve lo riscriverò. ${ }^{106}$
Capitán de Pons, piloto y capitán ${ }^{108}$ de la nave capitana.

92 Sic por «Ponçorone» (Punzorol).

93 Opto por «copiado» y no «traducido», pues parece evidente que el escribano de Ragusa se valió de la traducción al italiano enviada por Bannisio.

104 Literalmente «per fratt», seguido de una abreviatura que se empleaba para denotar la terminación adverbial «-mente»: esto es, «per frattmente», que en principio no tiene sentido. Quizá sea legítimo interpretar que lo que quiso escribir el escribano fue «per frettamente», esto es «por rapidez excesiva». La palabra «frettamente» está atestiguada con ese significado en una Biblia en toscano del siglo XIV-XV, según Tesoro della lingua Italiana delle Origine, 1997, s. v. «frettamente». Disponible en: http://pluto.ovi.cnr.it/btv/BJ1 [Consultado: 17/10/2020].

106 Este último párrafo transcrito en Gelcich, 1889, 2.

108 Recuérdese lo dicho en la nota 81 a propósito del significado de «governatore» (italiano) / «governatòr» (véneto). 


\section{Referencias bibliográficas}

Aguinagalde Olaizola, Borja, «Las dos “cartas” que escribió el capitán Juan Sebastián de Elcano a su regreso», en Redondo, Dionisio (ed.), La primera vuelta al mundo. Edición conmemorativa del V Centenario del viaje de Magallanes y Elcano, 1519-1522, Madrid, Taberna Libraria, 2019, 145-176.

Arquivo Nacional da Torre do Tombo, As gavetas da Torre do Tombo, IV (gaveta XV, maços 1-15), Lisboa, Centro de Estudos Históricos Ultramarinos, 1964.

Arquivo Nacional da Torre do Tombo, As gavetas da Torre do Tombo, VII (gaveta XVII, maços 3-9), Lisboa, Centro de Estudos Históricos Ultramarinos, 1968.

Arquivo Nacional da Torre do Tombo, As Gavetas da Torre do Tombo, VIII (gaveta XVIII, maços 1-6), Centro de Estudos Históricos Ultramarinos, Lisboa, 1970.

Avonto, Luigi, I compagni italiani di Magellano, Maldonado (Uruguay), Ediciones El Galeón, 1992.

Baldelli Boni, Giovanni Battista, Il milione di Marco Polo, Florencia, Da'torchi di G. Pagni, 1827.

Barros, João de, Terceira decada da Asia, Lisboa, Imprenta de Ioam de Barreira, 1563.

Boerio, Giuseppe, Dizionario del dialetto veneziano, Venecia, Reale Tipografia di Giovanni Cecchini editore, 1867.

Castro, Xavier de, et al., Le voyage de Magellan (1519-1522): la relation d'Antonio Pigafetta et autres témoignages, París, Michel Chandeigne, 2007.

Comellas, José Luis, La primera vuelta al mundo, Madrid, Rialp, 2012.

Contarini, Pietro, Dizionario tascabile delle voci e frasi particolari del dialetto Veneziano, Venecia, Giovanni Cecchini editore, 1850.

Elcano, Juan Sebastián et al., La primera vuelta al mundo, Madrid, Ediciones Miraguano/Ediciones Polifemo, 2012 [s. XVI].

Fernández de Navarrete, Manuel, Colección de los viajes y descubrimientos que hicieron por mar los españoles desde fines del siglo XV, Madrid, Imprenta Nacional, 1837, tomo IV.

Foretic, Vinko, «Cinjenice i Pretpostavke: Veze starih Dubrovcana's novootkrovenim zemljama o njihovo iseljavanje», Matica, Iseljenicki Kalendar, Zagreb, 1960, 142-153.

Gavrilovic, Stoyan, «Important References to Exploration, Science, Technology, and Hispanic American History in Yugoslav Archives», Proceedings of the Pennsylvania Academy of Science, 36, State College, 1962, 22-29.

Gavrilovic, Stoyan, «Documents in the Archives of Ragusa on Magellan's Voyage», Hispanic American Historical Review, 45:4, Durham, 1965, 595-608.

Gelcich, Eugene, «Zwei briefe über die Maghellanische Weltumseglung», Sitzungsberichte der Philosophisch-Historischen Classe der Kaiserlichen Akademie der Wissenschaften, Band CXIX, Viena, Academia Imperial de Ciencias, 1889, IV Tratado, 1-14. Disponible en: https://ia802205.us.archive.org/35/ 
items/sitzungsbericht332klasgoog/sitzungsbericht332klasgoog.pdf [Consultado: 12/03/2020].

Grupo de Trabajo de Catalogación de Manuscritos, «Normas de transcripción paleográfica», en Jornadas de Cooperación Bibliotecaria de 2001, Granada, 2001. Disponible en: culturaydeporte.gob.es/dam/jcr:b5d86054-cd59-4dff90c8-c397d8e09549/informe-catalogacion-de-manuscritos2001.pdf [Consultado: 12/03/2020].

Harrisse, Henry, The Discovery of North America, Londres/París, H. Stevens \& Son/H. Welter, 1892.

Herrera, Antonio de, Historia general de los hechos de los castellanos en las Islas y Tierra Firme del Mar Océano, Madrid, Imprenta Real, 1601.

Hugues, Luigi, «Juan Bautista Genovese. Notizie summarie», en Raccolta di documenti e studi pubblicati dalla R. Commissione Colombiana pel quarto centenario dalla scoperta dell'America, parte V, vol. II, Roma, Ministero della Pubblica Istruzione, 1894, 252-262.

Kunčević, Lovro, «Janus-faced Sovereignty: The International Status of the Ragusan Republic in the Early Modern Period», en Kármán, Gábor y Kunčević, Lovro (eds.), The European Tributary States of the Ottoman Empire in the Sixteenth and Seventeenth Centuries, Leiden/Boston, BRILL, 2013, 91-121.

Lopes de Castanheda, Fernão, História do descobrimento e conquista da Índia pelos portugueses, 8 vols., Coímbra, Imprenta de Ioam de Barreira, 1554.

Madunić, Domagoj, «The Defensive System of the Ragusan Republic (c. 15801620)», en Kármán, Gábor y Kunčević, Lovro (eds.), The European Tributary States of the Ottoman Empire in the Sixteenth and Seventeenth Centuries, Leiden/Boston, BRILL, 2013, 341-372.

Mafra, Ginés de, «Relación» [c. 1540], en Elcano, Juan Sebastián et al., La primera vuelta al mundo, Madrid, Ediciones Miraguano/Ediciones Polifemo, 2012, 139-183.

Mártir de Anglería, Pedro, Décadas del Nuevo Mundo, Buenos Aires, Editorial Bajel, 1944 [1. ${ }^{\mathrm{a}}$ ed. 1550].

Mazón Serrano, Tomás, Elcano, viaje a la historia, Madrid, Ediciones Encuentro, 2020.

Medina Zavala, José Toribio, El descubrimiento del océano Pacífico: Vasco Núñez de Balboa, Fernando de Magallanes y sus compañeros. Fernando de Magallanes. Santiago de Chile, Imprenta Universitaria, 1920a.

Medina Zavala, José Toribio, El descubrimiento del océano Pacífico. Hernando de Magallanes y sus compañeros. Documentos, Santiago de Chile, Imprenta Elzeviriana, 1920b.

Miguel, Raimundo de y Marqués de Morante, Nuevo diccionario latino-español etimológico, Leipzig, Imprenta de F. A. Brockhaus, 1867.

Oliveira, Fernão de, The voyage of Ferdinand Magellan = Viagem de Fernão Magalhães [c. 1570], edición del manuscrito portugués original custodiado en 
la Biblioteca de la Universidad de Leiden (Pierre Valière, 1976), traducido al inglés (Peter Schreurs, 2002), Manila, The National Historical Institute, 2002.

Pessagno, Giuseppe, Reseña de «Noberasco, Filippo, Un compagno di Magellano: Leon Pancaldo Savonese, Savona, Tipografia Savonese, 1929», Giornale storico e letterario della Liguria, Nuova Serie, Anno VII, Génova, 1930, 78.

Pigafetta, Antonio, «Primer viaje en torno del globo» [c. 1522], en Elcano, Juan Sebastián et al., La primera vuelta al mundo, Madrid, Ediciones Miraguano/ Ediciones Polifemo, 2012, 185-325.

Piloto genovés anónimo, «Navegaçam e vyagem que fez Fernando de Magalhães de Sevilha pera Maluco no anno de 1519 annos» [c. 1522], en Raccolta di documenti e studi pubblicati dalla R. Commissione Colombiana pel quarto centenario dalla scoperta dell'America, parte III, vol. II, Roma, Ministero della Pubblica Istruzione, 1893, 272-287.

Piloto genovés anónimo, «Navegación y viaje que hizo Fernando de Magallanes desde Sevilla para el Maluco en el año 1519» [c. 1522], en Elcano, Juan Sebastián et al., La primera vuelta al mundo, Madrid, Ediciones Miraguano/ Ediciones Polifemo, 2012, 117-137.

Polić Bobić, Mirjana, «En torno a las relaciones entre la república de Ragusa y la corona española en el siglo XVI: lo hecho y lo que queda por hacer», Verba hispanica: Anuario del Departamento de la Lengua y Literatura Españolas de la Facultad de Filosofía y Letras de la Universidad de Ljubljana, 1, Liubliana, 1991, 111-118.

Raccolta di documenti e studi pubblicati dalla R. Commissione Colombiana pel quarto centenario dalla scoperta dell'America, parte III, vol. I, Roma, Ministero della Pubblica Istruzione, 1892.

Raccolta di documenti e studi pubblicati dalla R. Commissione Colombiana pel quarto centenario dalla scoperta dell'America, parte V, vol. III, Roma, Ministero della Pubblica Istruzione, 1894.

RAE (Real Academia Española), Diccionario de la Lengua Española, 23. ${ }^{a}$ ed. [versión 23.4, actualización 2020, en línea], Madrid, Real Academia Española, 2014. Disponible en: https://dle.rae.es [Consultado: 13-01-2020].

Rill, Gerhard, «Bannisio, Iacopo», Dizionario Biografico degli Italiani, vol. 5, Roma, Istituto della Enciclopedia Italiana fondata da Giovanni Treccani, 1963. Disponible en: http://www.treccani.it/enciclopedia/iacopo-bannisio_ (Dizionario-Biografico)/ [Consultado: 30/06/2020].

Salas, Alberto, Tres cronistas de Indias: Pedro Mártir de Anglería, Gonzalo Fernández de Oviedo, fray Bartolomé de las Casas, México/Buenos Aires, Fondo de Cultura Económica, 1986.

Schmeller, Johan Andreas, «Über einige ältere handschriftliche Seekarten», Abhandlungen der I. Abt. der Kgl. Bayerischen Akademie der Wissenschaften, Múnich, Real Academia de Ciencias de Baviera, 1844, 269-273. 
Stuard, Susan Mosher, A State of Deference: Ragusa/Dubrovnik in the Medieval Centuries, Philadelphia, University of Pennsylvania Press, 1992.

Tadic, Jorjo, «Dva pisma o Magelanovom putovanju», Jadranska Straza, IX, sep., Split, 1931, 239-241.

Tesoro della lingua Italiana delle Origine, Paolo Squillacioti (dir.) [versión actualizada 2020, en línea], Italia, 1997. Disponible en: http://tlio.ovi.cnr.it/TLIO [Consultado: 18/06/2020].

Tognetti, Giampaolo, Criteri per la trascrizione di testi medievali latini e italiani, Roma, Arquivi di Stato, 1982.

Traduttore veneto, en Lingua Veneta [página web], Italia, Consiglio Regionale del Veneto, s/f. Disponible en: http://www.linguaveneta.net/strumenti/traduttore/ [Consultado: 18/06/2020].

Treccani. Istituto della Enciclopedia Italiana fondata da Giovanni Treccani, Vocabolario on line, Roma, s/f. Disponible en: http://www.treccani.it [Consultado: 18/06/2020].

Valbuena, Manuel, Diccionario universal latino-español, Madrid, Imprenta Real, 1808.

Vázquez Campos, Braulio, «La nao Trinidad: la otra vuelta al mundo», en Vázquez, Braulio (ed.) El viaje más largo: la primera vuelta al mundo, Madrid, Acción Cultural Española, 2019, 301-307. 